\title{
DESAFIOS PARA A GESTÃO HÍDRICA EM BACIA HIDROGRÁFICA DE RIO FEDERAL: A INTERLOCUÇÃO ENTRE ESTADO, TERRITÓRIO E SOCIEDADE
}

\author{
Marcia Eliane Silva Carvalho ${ }^{(a)}$ \\ (a) Departamento de Geografia, Mestrado Profissional em Rede Nacional para o Ensino das Ciências Ambientais, \\ Universidade Federal de Sergipe, Email: marciacarvalho_ufs@yahoo.com.br
}

\section{EIXO: BACIAS HIDROGRÁFICAS E RECURSOS HÍDRICOS: ANÁLISE, PLANEJAMENTO E GESTÃO}

\begin{abstract}
Resumo
Tomando como pressuposto que a tríade Estado-Território-Sociedade é base para o entendimento e efetivação da gestão das águas na unidade bacia hidrográfica, este artigo tem como objetivo analisar os desafios da gestão hídrica em bacia de rio federal a partir de três vieses: Estado, via políticas públicas de ordenamento do uso dos recursos hídricos; Território, enquanto base física e lócus das relações de poder e Sociedade, enquanto partícipe da gestão hídrica. Para tal, foram realizados levantamentos bibliográficos e pesquisas em fontes primárias e secundárias, tendo sido tomada como foco de análise a bacia do rio Vaza Barris em Sergipe. Os resultados demonstraram que as ações políticas voltadas para a gestão hídrica na referida bacia ainda são incipientes e que os atores sociais desconhecem as questões pertinentes a gestão das águas, indicando a necessidade de efetivar ações, sobretudo no âmbito local, com a valorização dos territórios existentes na unidade de bacia hidrográfica.
\end{abstract}

Palavras chave: Gestão Hídrica, Estado, Território, Participação Social.

\section{Introdução}

Um dos grandes desafios das políticas públicas continua estando ligada à gestão racional e participativa dos recursos hídricos, pois a água além de ser essencial para a sobrevivência do ser vivo, é um recurso limitado e base indispensável para a maioria das atividades produtivas humanas.

Neste sentido, o tripé Estado / Território / Sociedade emerge como base para efetivar a gestão participativa: o Estado, via políticas públicas de ordenamento do uso dos recursos hídricos; a Sociedade, enquanto partícipe efetiva de diferentes representantes na gestão hídrica e o Território, enquanto base física e lócus das relações de poder.

Esta tríade torna-se grande desafio para a gestão no que concerne às bacias de rio federal, visto que em determinados casos a efetivação do processo de gestão participativa fica na dependência dos entes federados em dialogarem e efetivarem a instituição do gerenciamento da bacia como um todo e dos recursos hídricos em específico. 
Assim, este artigo tem como objetivo analisar a gestão hídrica a partir do entendimento da tríade Estado / Território / Sociedade, tomando como lócus de análise a bacia sergipana do rio Vaza Barris, visando identificar a importância do estudo em âmbito local em contraponto com as proposições atuais da dimensão federal como única possibilidade de gestão para bacias que abrangem mais de uma unidade estadual. Ao mesmo tempo, o recorte no estado de Sergipe tem apresentado elevado crescimento populacional nos últimos anos, bem ampliação das pressões antrópicas a ele associado. Para tal, foram realizados levantamento de dados em fontes primárias e secundárias.

A bacia do rio Vaza Barris abrange os estados da Bahia e Sergipe. O seu alto e médio curso localiza-se no estado da Bahia e é considerado como intermitente, tendo seu aproveitamento hídrico relacionado a existência de barragens. O seu baixo curso, todo perene, objeto deste estudo, localiza-se em Sergipe, ocupando uma área de $2.559,0 \mathrm{~km}^{2}$. Apresenta uma população total em torno de 300 mil habitantes, distribuídos em 14 municípios ao longo de três Mesorregiões: Sertão, Agreste e Leste Sergipano, o qual abrange a Zona de Expansão de Aracaju. Dos municípios integrantes da bacia na porção sergipana, Pedra Mole, Pinhão, Macambira, Campo do Brito e São Domingos estão totalmente inseridos na bacia e outros nove parcialmente abrangidos, sendo que dentre estes as sedes municipais de Frei Paulo, Carira, São Cristóvão e Itaporanga d'Ajuda localizam-se dentro dos limites da bacia (CARVALHO, 2010).

\section{O Território e a Gestão Hídrica em Bacia Hidrográfica}

Para o entendimento da importância da bacia hidrográfica no que se refere ao planejamento e gestão das águas, torna-se pertinente compreendê-la enquanto um recorte físico-territorial de um determinado espaço geográfico construído histórico e socialmente.

Compreende-se, portanto, que a categoria território torna-se base para o entendimento da questão ambiental e hídrica em especial, pois nele efetiva-se a interação entre o físico e o social, emergindo relações de poder em função das desigualdades em termos de apropriação e uso dos recursos naturais: “o território reflete a diferente espacialização dos processos de modernização, bem como os ritmos e padrões de degradação" (CUNHA e COELHO, 2005, p. 44).

A categoria território apresenta-se importante para os estudos geográficos em função do

(...) seu significado concreto, o que envolve não apenas o aspecto físico ou material, mas também tudo o que uma sociedade pode comportar como ideal, como representações, sentimentos de vinculação, de comportamentos individuais ou de instituições que participam de uma organização espacial... Analisar concretamente o território significa entendê-lo como um produto da história da sociedade, e que, portanto, está em constante modificação. Ele é o resultado de um processo de apropriação de um grupo social e do 
quadro de funcionamento da sociedade, comportando, assim, ao mesmo tempo, uma dimensão material e cultural dadas historicamente (MACHADO, 1997, p.27).

De acordo com Santos e Silveira (2005, p. 301), o conceito de território geralmente está associado à idéia de espaço apropriado e utilizado, valorizado ou desvalorizado a depender da lógica vigente:

O território é uno, o que significa que o seu movimento é solidário. Desse modo, desvalorizações e revalorizações obedecem a uma mesma lógica. Dir-se-ia que certas frações do território aumentam de valor em dado momento, enquanto outras, ao mesmo tempo e por via de conseqüência, se desvalorizam.

O conceito de território deve então abarcar tanto o espaço físico quanto as relações que se estabelecem pela apropriação de seus atributos, perpassando pela questão do poder, seja ela ligada ao papel exercido pelo Estado ou pelo capital privado.

Haesbaert (2007) ressalta que embora a concepção de território como fonte de recursos naturais apropriação da natureza - seja pouco utilizada, não significa que estas características não estejam presentes em certos grupos sociais que apresentam estreita relação com a terra, em seu sentido físico.

Assim, a categoria território, ao englobar aspectos naturais, sociais, culturais, econômicos e políticos, nos quais emanam relações de poder através de entes gestores de diferentes escalas, torna-se componente fundamental nos estudos que visam a gestão ambiental, em decorrência desta envolver necessariamente todos os aspectos supracitados.

No que concerne ao uso dos recursos naturais, o território encontra-se na interface entre o Estado e a gestão ambiental, pois

(...) as questões do controle, do ordenamento e da gestão do espaço têm sido sempre centrais nas discussões sobre território. Como elas não se restringem, em hipótese alguma, à figura do Estado, e hoje, mais do que nunca, precisam incluir o papel gestor das grandes corporações industriais, comerciais, de serviços e financeiras, é imprescindível trabalhar com o território numa interação entre as múltiplas dimensões sociais (Haesbaert, 2007, p.52).

Desta forma, o território, apresentando variedade de recursos, apresenta as diferentes espacializações da produção dos sujeitos sociais como também os ritmos e padrões de deterioração do meio ambiente. Assim sendo, para gerir os recursos hídricos faz-se necessário selecionar um recorte territorial que concilie os atributos físicos aos socioeconômicos e políticos.

Nestes termos, a bacia hidrográfica tem sido indicada mundialmente e destacada por vários autores (dentre eles, LEAL, 2000; CARRERA-FERNANDEZ, 2002; TUNDISI, 2005; SILVA e PRUSKI, 2005), como a 


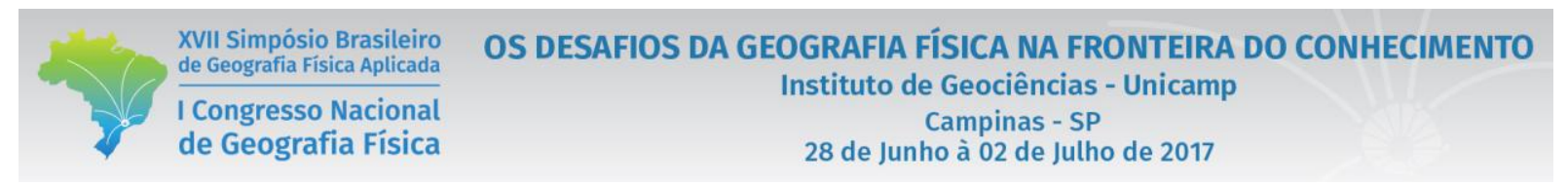

unidade territorial de planejamento e gestão dos recursos hídricos, devido à repercussão integrada dos agentes naturais e antrópicas no espaço em questão.

Por outro lado, Mendonça e Santos (2006, p. 110) levantam algumas questões acerca da unanimidade em adotar a bacia de drenagem como unidade de planejamento das águas, salientado que a dinâmica ambiental e dos componentes sociais, econômicos e culturais nem sempre apresentam a mesma amplitude da bacia:

\begin{abstract}
Embora considerada unidade ideal para gestão dos recursos hídricos a bacia hidrográfica não insere, de maneira satisfatória, as várias dimensões da manifestação espacial dos diversos componentes da gestão das águas. Veja-se, por exemplo, o próprio fluxo da água que possui uma dinâmica mais ampla que a bacia (águas subterrâneas, captação alóctone para abastecimento e irrigação, esgotamentos externos, transposição de águas, etc), além do que o clima, a vegetação, os solos, etc., bem como a paisagem e o geossistema, têm estruturação espacial cuja delimitação não se faz pela mesma da bacia hidrográfica. Mais grave ainda soa as dimensões espaciais das estruturas sociais, tais como a administrativa (nação, estado e municípios), econômica (mercados, produtores, consumidores, etc.), e cultural (práticas cotidiana) do território, que não se fazem, de maneira geral, em conformidade com as bacias hidrográficas.
\end{abstract}

No entanto, os referidos autores consideram que, mesmo com esta variada superposição de delimitações do espaço / território, a opção pelas bacias sustenta-se pela ausência de um outro tipo de unidade que considere os recursos hídricos em sua totalidade.

De acordo com a $\operatorname{OECD}(2015$, p. 47):

A formulação e a implementação das políticas de recursos hídricos são, por natureza, altamente fragmentadas e envolvem uma infinidade de partes interessadas e autoridades dos diferentes níveis de governo e áreas de política. Do ponto de captação da água para qualquer tipo de uso até as extremidades da bacia hidrográfica (e além), existe um espaço cheio de fronteiras políticas e administrativas que correspondem às instituições que são relevantes e que têm voz no processo de gestão. Nesse contexto, é essencial mapear claramente as autoridades responsáveis e suas atribuições, como também é fundamental a gestão efetiva das suas interações e interdependências.

Neste ínterim, o gerenciamento dos recursos hídricos em bacias de rios de domínio da União vem se somar a estes desafios, visto que o reconhecimento da bacia hidrográfica como unidade de planejamento e gestão das águas não obedece aos critérios político-administrativos dos municípios, o que pode gerar tanto o conflito quanto superposição de poderes ao tentar geri-lo.

Para Mascarenhas (2008), o Pacto de Gestão de Águas é considerado como uma estratégia para superar os impasses entre os entes envolvidos no sistema de gestão da bacia, buscando apresentar resultados mais efetivos. O principal objetivo do Pacto Nacional pela Gestão das Águas é a construção de compromissos entre os entes federados, visando à superação de desafios comuns e à promoção do uso múltiplo e 
sustentável dos recursos hídricos. Um desafio que necessita ainda ser melhor avaliado no que tangue a sua importancia enquanto instrument de efetivação do processo de gestão.

Vale ressaltar que, ao adotar a bacia de drenagem como unidade de gestão, faz-se necessário valorizar os territórios nela inseridos, buscando integrar ao processo de gestão os sujeitos sociais dos referidos territórios, suas práticas, conhecimentos, culturas, fato este ainda nao concretizado na gestão hidrica do Brasil.

\section{Estado, Políticas Públicas e Gestão Hídrica}

O Estado, inegavelmente, destaca-se enquanto ente gestor dos recursos naturais de determinada porção territorial, embora este apresente, na atualidade, políticas públicas neoliberais que valorizam privatizações e a não efetivação do poder estatal.

Isto nos remete a crise capitalista da década de 70 que provocou a retomada de concepções liberais, pautadas em um Estado com o mínimo de responsabilidades sociais, deixando a economia local sob a égide do mercado financeiro internacional (global) (CAMPOS FILHO, 2001).

As ações estatais voltadas para descentralização foram institucionalizadas na Constituição de 1988 e vem ganhando corpo com as políticas neoliberais. Isto significa que o Estado

(...) não é mais a única representação do político nem a única escala de poder, mas certamente é uma delas, mantendo-se ainda, embora com novas formas e funções. A forma de sua reconstrução e de sua permanência é a sua privatização e emergência de uma nova relação público-privada. Grandes corporações e bancos tomam as decisões e as executam, assumindo funções de governo, e tornando-se componente do Estado contemporâneo; por outro lado, os conflitos no governo do território exigem a participação crescente da sociedade civil nas decisões e ações. Trata-se, em suma, de compartilhar decisões e ações num novo modo de regulação. Se o Estado deixa de ser o executor exclusivo dos processos econômicos e políticos, acumula, em contrapartida, funções de coordenação e regulação crescentes, para fixar as regras básicas das parcerias (BECKER, 2005, p.299).

O papel do Estado em nosso país tem-se pautado na estruturação de políticas públicas de produção e de reprodução do espaço cuja intenção é ser parceiro

(...) no processo de competitividade sistêmica e de coesão dos espaços ocupados, em suas mais diferentes escalas sem, contudo, assumir o papel de líder condutor do processo a não ser o de coadjuvante, embora entenda o grave problema de desequilíbrio social, econômico e ambiental que pode ser traduzido como a ausência da sustentabilidade humana para a maioria da população brasileira (MIORIN, 2003, p.108). 
Em concordância com Ianni (1991, p.274) o Estado tem manipulado o setor econômico do país, visando expandir o capital privado nacional e estrangeiro:

(...) o Estado foi levado a interferir de modo crescente na economia, principalmente para aperfeiçoar as condições propícias aos investimentos e negócios privados. Por outro lado, o poder público reelaborou e aperfeiçoou as garantias políticas, para que os investidores estrangeiros pudessem sentir os seus interesses assegurados.

Diante desta realidade, o mercado e o consumidor passaram a ser condicionados por mecanismos pautados na ideologia da globalização, que, em grande parte, gera necessidades ilusórias e trazem como conseqüências o consumismo desenfreado por bens materiais e a degradação ambiental.

Neste ínterim, Becker (2005) atenta para que o fato de a internacionalização da economia tende a superar os Estados, enquanto único órgão gestão dos bens territoriais locais, e suas fronteiras, acarretando em uma nova visão territorial do trabalho e uma nova geopolítica, valorizando territórios em função de seus atributos naturais e tecnológicos associados à iniciativa política.

Associando estas questões aos recursos hídricos, pode-se antever que territórios dotados de um excedente hídrico sejam alvo de interesses internacionais que, através de instrumentos geopolíticos, busquem, além de seus espaços nacionais, reservas deste recurso via mercantilização da água.

No tocante as relações entre a sociedade e o meio ambiente, a base política, socioeconômica e cultural de um país constitui característica decisiva na utilização racional ou não dos recursos naturais. Para Mantovaneli Júnior (2006), o que caracteriza o século XXI é a crise de legitimidade e de competência do Estado associado a uma sociedade civil mais organizada, presente e dinâmica.

Desta forma, as políticas públicas devem ter (ou pelo menos deveriam ter) papel preponderante nestas relações, pois visam a organização espacial das atividades econômicas e sociais e a compatibilização dos recursos naturais com os interesses da sociedade.

A perspectiva de uma gestão descentralizada e participativa dos recursos hídricos emerge em um momento em que o papel do Estado, diante das políticas neoliberais, não mais atua como único ente regulador e promotor do bem estar social, repartindo com a sociedade funções anteriormente somente cabíveis ao poder público e priorizando por outro lado, "uma economia de mercado perante o sistema financeiro internacional, com ampla cobertura comercial e privatizações” (LISBOA, 2007, p. 135).

Neste contexto, e corroborando com estas análises, encontra-se a gestão dos recursos hídricos. O Estado busca, através dos princípios de democratização do acesso ao uso da água e do aumento da participação da sociedade civil organizada, legitimado pela Lei 9.433/97, que institui a Política Nacional de Recursos 
Hídricos e cria o Sistema Nacional de Recursos Hídricos, compartilhar as decisões e ações no âmbito da gestão das águas.

Entendendo que o próprio Estado pode atuar na valorização de determinadas porções de seu território, a partir da implementação de infra-estrutura básica de saneamento e transporte, o conhecimento das políticas públicas e de seus desdobramentos na organização espacial territorial torna-se peça fundamental no entendimento da gestão dos recursos hídricos no âmbito de uma bacia hidrográfica.

Deve-se considerar também que tais políticas podem ordenar ou não o uso dos recursos naturais, como também podem ter diferentes repercussões a partir da escala de análise, ao mesmo tempo em que os marcos regulatórios podem ser efetivados ou não. Neste sentido,

(...) temos que reconhecer as pressões exercidas por políticas setoriais, no sentido de permitir o máximo aproveitamento dos recursos naturais existentes no país, com vistas a atender os objetivos da economia capitalista. Para isso o papel do Estado é central, pois é dele que emanam as diretrizes maiores que estão presentes nas políticas públicas (ORLANDO, 2006, p.63).

Revestida de caráter neoliberal, a legislação em pauta (em âmbito federal e nas estaduais) pertinente aos recursos hídricos legitima um Estado descentralizado, mas que atua como gestor das águas, determinando os usos e os fiscalizando, e que por outro lado dissemina a ideia de participação, que em muitos casos não se efetiva. Este é um dos grandes gargalos da gestão hídrica.

Oliveira (2010) traz para o debate as contradições entre a questão da governança e a participação social, pois para a autora é o Estado que determina quem, quando, por quanto tempo e que tipo de consumo se dará para determinado corpo hídrico. Há, portanto, um falso discurso da responsabilidade social, que mascara interesses particulares (capitalistas).

A autora supracitada ressalta também, assim como Ribeiro (2008) e Orlando (2006), dentre outros, que a legislação citada regulamentou a água como mercadoria, em função da mesma ser designada como um bem econômico.

No entanto, é importante destacar que a água também é caracterizada como um bem público, finito e não alienável, cujos usos degradantes atuais se tornarão irreversíveis em função do crescimento populacional e da necessidade premente de novos espaços tanto para a reprodução social quanto para a própria produção de alimentos, fazendo-se mister ações visando minimizar este estágio de degradação atual.

Assim, se por um lado há o reconhecimento do controle estatal sobre as águas, por outro acreditasse que com a efetivação dos Comitês de Bacia Hidrográfica, definindo as prioridades de usos na bacia, possibilita a participação da sociedade minimizando os interesses particulares, além de fornecer dados para o órgão 
gestor deliberar os usos, que a priori devem ser estabelecidos no Plano de Recurso Hídrico da bacia, construído pelo próprio Comitê.

Segundo Cunha (2003), os Comitês de Bacia Hidrográfica são fundamentais para a implementação da Política Nacional dos Recursos Hídricos, pois envolve a sociedade em questões pertinentes aos usos da água, vista na atualidade como em fase de escassez.

Estas reflexões apontam um encaminhamento: a necessidade de associar a atuação do Estado, via políticas públicas, com as necessidades da sociedade civil, não apenas das grandes empresas capitalistas, mas sim do cidadão comum que vive uma realidade muitas vezes de exclusão social e de degradação ambiental. Necessidade esta cada vez mais longe de ser atingida.

\section{A sociedade no processo de gestão hídrica: os sujeitos sociais e a não gestão hídrica na bacia do rio Vaza Barris}

A proposta de gestão participativa apontada na legislação em vigor está vinculada principalmente na efetiva participação da sociedade civil nos Comitês de Bacias Hidrográficas que integra o Sistema Nacional de Gerenciamento de Recursos Hídricos, juntamente com o Conselho Nacional, dos Estados e do Distrito Federal de Recursos Hídricos, além dos órgãos públicos cujas competências estejam vinculadas a gestão dos recursos hídricos.

As contradições entre o discurso político e a realidade da bacia do rio Vaza Barris revelam-se no momento em que identificamos que os sujeitos sociais não têm participação política, desconhecendo as questões pertinentes à gestão das águas, pois esta inexiste na bacia.

As políticas públicas referentes aos recursos hídricos são de desconhecimento da maior parte dos responsáveis pelas questões ambientais em nível municipal. O comitê de bacia hidrográfica que, de passagem, seria um lócus de representação dos usuários de água e da sociedade civil, não está estruturado. Conseqüentemente também não existe o plano de bacia e nem a participação cidadã no tocante as questões hídricas locais.

Em pesquisa realizada por Carvalho (2010) em nove municípios sergipanos integrantes da bacia do rio Vaza Barris, foi identificado que $66,7 \%$ dos representantes políticos municipais desconhecem as Políticas Nacional e Estadual de Recursos Hídricos (entrevistados de Frei Paulo, Pedra Mole, Macambira, São Domingos, Campo do Brito e Itabaiana); 11,1\% já ouviu falar (representante de Carira), mas não a conhecem em detalhes e apenas 22,2\% a conhecem em detalhes (entrevistados de São Cristóvão e Aracaju). 
Esses dados revelam que em âmbito municipal os gestores não se encontram preparados para aplicá-la, pois a maioria desconhece do que se trata. Conseqüentemente sobre as dificuldades para implementá-la no município, sete dos entrevistados não responderam a esta questão e dois entrevistados afirmaram que é o próprio desconhecimento da temática.

Sobre as principais ações referentes à gestão hídrica no âmbito municipal, 77,8\% afirmaram que não há ações neste sentido em seus municípios; $11,1 \%$ (São Cristóvão) está em processo de construção destas ações e outros 11,1\% (Aracaju, capital do estado) apresenta ações concretas (CARVALHO, 2010).

Estes dados apontam que na maioria dos municípios integrantes da bacia do rio Vaza Barris em Sergipe o debate sobre a questão hídrica ainda está longe de se iniciar e mais longe ainda de se efetivar, mesmo tendo a legislação e o debate sobre as águas datando de 1997.

Sobre o conhecimento e/ou a necessidade de instituição do Comitê de Bacia do rio Vaza Barris, 55,5\% assinalaram que desconhecem o que seja um comitê; 44,4\% afirmaram que é necessária sua estruturação e 1,1\% afirmou que não há necessidade deste Comitê no município (CARVALHO, 2010).

Quando questionados sobre a participação dos mesmos em ações voltadas para a gestão hídrica no município, 88,8\% afirmaram que não participam, pois inexistem. Os representantes do DESO Companhia de Saneamento de Sergipe e da COHIDRO - Companhia de Desenvolvimento de Recursos Hídricos e Irrigação de Sergipe, afirmaram que os respectivos órgãos realizam atividades junto aos usuários visando a orientação sobre o uso racional das águas.

Embora os afluentes e o próprio rio Vaza Barris seja utilizado pela população local para usos associados com a dessedentação animal, pesca, lazer e irrigação, são considerados usos de pequeno porte e há uma desarticulação entre Sergipe e Bahia para a implementação de ações coletivas para efetivar a instituição da gestão hídrica nesta bacia. Por ser a mesma uma bacia de rio de águas de domínio da União, a sugestão dada é que a Agência Nacional de Águas (ANA) inicie o processo junto aos dois estados, fato ainda não efetivado.

Em um momento atual no qual a geopolítica das águas alerta para a escassez da mesma, em que são definidas as prioridades de uso, os conflitos e a necessidade de gerir todo e qualquer tipo de recurso hídrico, é no mínimo negligente ignorar o potencial hídrico desta bacia para o âmbito local.

Neste contexto, ressalta-se a importância de valorização do território, pois embora a bacia hidrográfica seja de rio federal, os mananciais que emergem no estado de Sergipe devem ser considerados como de competência deste estado em legislar sobre os mesmos, ou seja, não há impedimento legal em efetivar a gestão hídrica estadual a partir das sub e microbacias que estes mananciais formam. Efetiva-se desta 


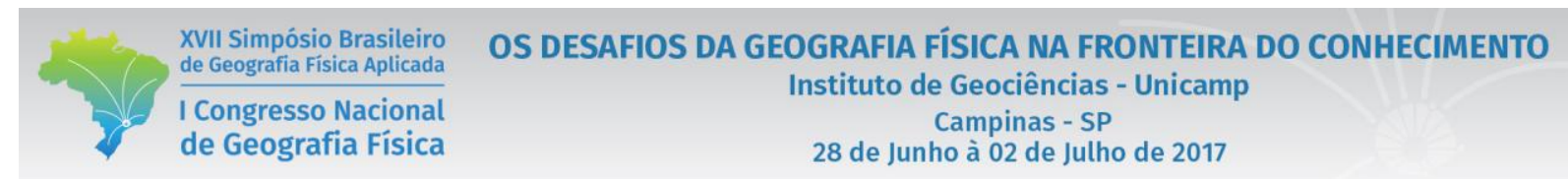

forma a importância do território na gestão hídrica. Ampliando o olhar para além da bacia hidrográfica, com a valorização dos componentes políticos no âmbito de um determinado território por ela abrangido.

Neste contexto vale destacar o exposto por Granja e Warner (2006, p. 9) acerca da inter-relação entre os segmentos social, político e institucional no tocante a hidropolítica do país:

Há problemas entre nosso sistema político e nosso arcabouço institucional de gerenciamento da água? Sim, inúmeros, mas não se pode perder de vista que as instituições (tanto políticas, quanto administrativas e de gestão da água) são produtos de nossos contextos, portanto, espelham nossas escolhas, amparadas pela força e poder dos atores do jogo social naquela situação.

Com a tomada de consciência que a água é um bem finito, e com a iminência de uma escassez hídrica em todo o planeta, tanto em quantidade como em qualidade, na bacia em questão este recurso não é devidamente valorizado, ocorrendo desperdícios e degradações.

Estas reflexões foram também abordadas por outros autores, a exemplo de Leal (1995), que considera a microbacia como lócus da efetivação das relações sociais; Orlando (2006) que aponta o fortalecimento da gestão em nível municipal como alternativa inicial para efetivar a gestão da bacia; e Oliveira (2007), que toma como exemplo o fortalecimento inicial dos atores sociais nas sub-bacias que compõem determinada bacia hidrográfica.

Oportunamente, concordamos com as considerações de Oliveira (2007, p. 188) quando afirma que

...as dificuldades para internalizar a bacia hidrográfica como território de gestão ainda persistem, mostrando-se que do ponto de vista operacional não tem sido possível desencadear as ações preconizadas de compartilhamento das responsabilidades entre os poderes (federal, estadual e municipal), usuários e a sociedade civil na execução das tarefas.

Desta forma, antes de chegarmos a uma gestão em esfera federal, deve-se iniciar um processo de gestão local, organização de seus usuários, capacitação de técnicos, estruturação de setores específicos sobre meio ambiente e neste sobre as águas, para que sejam promotoras e propagadoras do conhecimento gerado tanto na academia quanto na legislação para os cidadãos de determinada localidade. Fortalecendo o poder local, e dotando os atores sociais de conhecimentos concretos sobre a questão hídrica, pode-se chegar a uma gestão efetiva dos recursos hídricos, que saia do papel e chegue aos atores sociais.

Valorizar a participação dos municípios e cidades no processo de gestão hídrica significa igualmente dotá-los das condições necessárias par tal... A valorização da dimensão municipal no processo de gestão hídrica, se, por um lado, representa a incorporação de uma escala geográfica fundamental a essa discussão, por outro, pede um arranjo logístico capaz de viabilizar uma participação efetiva dessa esfera (ORLANDO, 2006, p. 197). 
Concordamos com Zinato (2005, p. 619) ao afirmar que "mobilizar uma comunidade não é uma tarefa tão simples quanto se desenhar um projeto técnico". Historicamente a sociedade civil esteve a margem das decisões políticas de seu próprio Estado, de seu próprio município, de seu próprio bairro e neste momento que é chamada a participar, ainda assim, desconhece o seu papel perante a temática em pauta.

\section{Considerações Finais}

O reconhecimento da existência de territórios no âmbito de uma bacia hidrográfica, dotados de poder e delimitados a partir das relações estabelecidas entre os sujeitos sociais e a produção do espaço, nos quais o recurso água é elemento primordial no desenvolvimento econômico, social e manutenção ecológica, deve ser valorizado no que concerne à gestão hídrica no âmbito da bacia hidrográfica, principalmente no nível federal.

Embora o poder público estadual busque efetivar a gestão hídrica em Sergipe, na bacia do Vaza Barris, este processo ainda é incipiente. Por ser considerada como federal, o processo de gestão está vinculado ao ente federal, revelando uma contradição entre a teoria e a prática, pois os problemas ambientais locais ainda não incitaram a efetivação do Comitê de bacia, lócus da participação cidadã e da busca para solução de problemas locais. Ao mesmo tempo, os atores sociais não têm participação política, desconhecendo as questões pertinentes à gestão das águas. Há ausência de ações efetivas no lócus municipal.

Estes dados indicam a necessidade de efetivar ações no âmbito municipal, a partir da valorização dos territórios, buscando meios e metas de envolvimento com a sociedade civil de forma mais efetiva e continua na busca para efetivar a gestão hídrica sobretudo em âmbito local.

Isto nos leva as considerações de Leff (2009) ao afirmar que para ocorrer a efetivação de uma gestão participativa e democrática dos recursos naturais, uma nova racionalidade ambiental deve ser construída a partir da desconstrução da racionalidade capitalista na busca de uma economia baseada na equidade e sustentabilidade. Assim, o desafio continua, após vinte anos da publicação da Lei das Águas do Brasil.

\section{Bibliografia}

BECKER, Bertha. A geopolítica na virada do milênio: logística e desenvolvimento sustentável. In: CASTRO, Iná Elias; GOMES, Paulo C. da C.; CORRÊA, Roberto Lobato. Geografia: conceitos e temas. 7.ed. Rio de Janeiro: Bertrand Brasil, 2005, p. 271-308.

CAMPOS FILHO, Romualdo P. Capitalismo, Globalização e o papel dos Estados Nacionais. In: Boletim Goiano de Geografia. Vol. 21, n.1, jan/jul, 2001, p. 99-117. 
CARRERA-FERNANDEZ, José; GARRIDO, Raymundo José. Economia dos recursos hídricos. Salvador: EDUFBA, 2002.

CARVALHO, M.E.S. A questão hídrica no Vaza Barris Sergipano. Tese de doutorado. São Cristóvão: UFS, 2010.

CUNHA, Luís Henrique; COELHO, Maria Célia N. Política e Gestão Ambiental. In: CUNHA, S.B.; CUNHA, Sandra Baptista da. Bacias hidrográficas. In: CUNHA, S.B.; GUERRA, A.J.T. Geomorfologia do Brasil. 3. ed. Rio de Janeiro: Bertrand Brasil, 2003, p. 229-272.

GRANJA, Baraglio; WARNER, Granja. A hidropolítica e o federalismo: possibilidades de construção da subsidiariedade na gestão das águas no Brasil? Revista de Administração Pública vol.40 n.6 Rio de Janeiro Nov./Dec. 2006, p.1-27.

GUERRA, A.J.T. A questão ambiental: diferentes abordagens. 2ed. Rio de Janeiro: Bertrand Brasil, 2005, p.4380.

HAESBAERT, Rogério. Concepções de territórios para entender a desterritorialização. In: SANTOS, Milton et. al. Território, territórios: ensaios sobre o ordenamento territorial. 3.ed. Rio de Janeiro: Lamparina, 2007.p.4371LEAL, Antonio Cezar. Gestão das Águas no Pontal do Paranapanema/SP. Instituto de Geociências. Campinas: Universidade Estadual de Campinas. Tese de Doutorado. 2000.

IANNI, Octavio. Estado e Planejamento econômico no Brasil. 5ª ed. Rio de Janeiro: Civilização Brasileira, 1991.

LEAL, Antonio Cezar. Meio ambiente e urbanização na microbacia do Areia Branca - Campinas/SP. Rio Claro: Universidade Estadual Paulista. Dissertação de Mestrado, 1995.

LEFF, Enrique. Saber ambiental: sustentabilidade, racionalidade, complexidade, poder. Tradução: Lúcia M.E. Orth. 7.ed. Petrópolis: Vozes. Rio de Janeiro, 2009.

LISBOA, Josefa Bispo de. A trajetória do discurso do desenvolvimento para o Nordeste: políticas públicas na (dis)simulação da esperança. Aracaju: NPGEO/UFS, 2007. Tese de Doutorado.

MACHADO, Mônica Sampaio. Geografia e Epistemologia: um passeio pelos conceitos de espaço, território e territorialidade. Revista GEO UERJ. Rio de Janeiro: UERJ, n.1, 1997, p. 17-32.

MANTOVANELI JÚNIOR, Oklinger. Políticas Públicas no século XI: a perspectiva da gestão multicêntrica. Blumenau: EDIFURB, 2006.

MASCARENHAS, Ana C. M. Conflito e Gestão de águas: o caso da bacia hidrográfica do rio São Francisco. Dissertação de Mestrado. Brasília: UNB, 2008.

MENDONÇA, Francisco; SANTOS, Leonardo J.C. Gestão da água e dos recursos hídricos no Brasil: avanços e desafios a partir das bacias hidrográficas. Geografia. Rio Claro: AGETEO, v.31, n.1, p. 103-118, jan/abr, 2006.

OECD. Governança dos Recursos Hídricos no Brasil, OECD Publishing, Paris. 2015.

OLIVEIRA, Marize L.V.M. Águas do Ceará: política pública de territorialidades conflituosas. Tese de doutorado. Núcleo de Pós-graduação em Geografia. São Cristóvão: UFS/NPGEO, 2010.

OLIVEIRA, Carlos Hermínio de A. Bacia hidrográfica e os territórios de gestão das águas - Estudo de caso: a sub-bacia hidrográfica do riacho Jacaré do Baixo São Francisco. Tese de doutorado. Núcleo de Pós-graduação em Geografia. São Cristóvão: UFS/NPGEO, 2007.

ORLANDO, P. H. K. A produção do espaço e gestão hídrica na bacia do rio Paraibuna (MG-RJ). Tese de Doutorado. Programa de pós-graduação em Geografia. Presidente Prudente: UNESP, 2006.

RIBEIRO, Wagner Costa. Geografia Política da Água. São Paulo: Annablume, 2008.

SANTOS, M.; SILVEIRA, M. L. O Brasil: território e sociedade no inicio do século XXI. Rio de Janeiro: Record, 2005.

SANTOS, Milton. A natureza do espaço: técnica e tempo, razão e emoção. São Paulo: Hucitec, 1996a.

SILVA, Demetrius David da.; PRUSKI, Fernando Falco. Gestão de Recursos Hídricos: aspectos legais, econômicos, administrativos e sociais. Viçosa: Universidade Federal de Viçosa, 2005. 


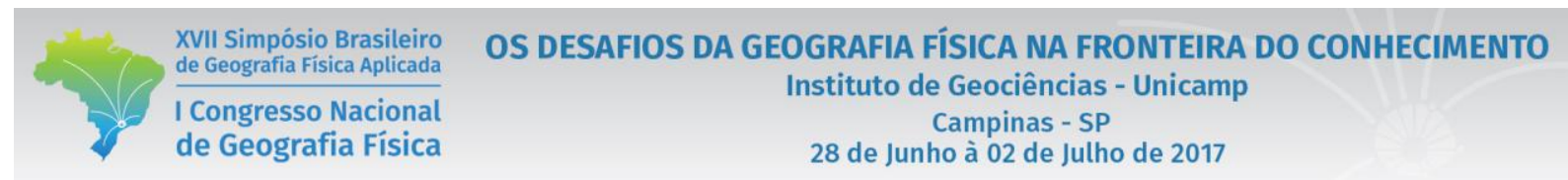

TUNDISI, José Galizia. Água no século XXI: enfrentando a escassez. 2.ed. São Paulo: Rima, 2005.

ZINATO, Maria do Carmo. A construção da cidadania propulsionada pela água. In: SILVA, Demetrius David da.; PRUSKI, Fernando Falco. Gestão de Recursos Hídricos: aspectos legais, econômicos, administrativos e sociais. Viçosa: Universidade Federal de Viçosa, 2005, p.619-659. 